\title{
Improving Financial Security Model under Sanctions as Sustainable Development Component
}

\author{
Valeriy Kopein ${ }^{1, *}$, Elena Filimonova ${ }^{1}$, Tatjana Sinitsyna $^{1}$, Tatjana Lantseva $^{1}$, and Nelli \\ Morozenko ${ }^{1}$ \\ *Kemerovo institute (branch) of Plekhanov Russian University of Economics, Department of Finance \\ and Banking, Kuznetsky pr.39, Kemerovo, Russia
}

\begin{abstract}
This article discusses theoretical and methodological issues of financial and food security, their interrelations with Sustainable development and assessment for Russian regions. It is emphasized that the global financial crisis and economic sanctions have had a substantial impact on the level of security in Russia and its regions. This negative impact is expected to worsen the environment protection and agriculture sector development, what can be the obstacle to sustainable development. The problems hampering the development of own agricultural production are described among which the problem of financing stands out. The conclusion states that there is an increased attention of the agricultural sector support despite their uneasy financial situation. The article underlines the issue of the empirical failure of regional financial independence from the state which complicates the determination of parameters of financial security of the region. The attention is drawn to the link between food security and financial independence of the region
\end{abstract}

\section{Introduction}

The impact of the sanctions levied on the Russian economy are studied by many institutions and researchers, although the views on the damage to Russia and the countries imposing sanctions vary significantly $[1,2,3]$.The sanctions showed that the Russian economy is sufficiently sensitive to external influences as a number of experts state $[4,5]$. But Russian economy is heavily burdened by internal problems. Today there is the destruction of raw materials and export model of the Russian economy and an evolution of a new model of development [6]. A special role in this process is given to the import substitution in all industries. Import substitution which was defined as a strategic line of development in the coming years, has brought certain results.

The best changes and dynamics are demonstrated by the agricultural sector. But we shouldn't overestimate the positive impact of Russia's economic sanctions and Russia's measures (embargo). The researchers note that the effect of the embargo was blurred by the

\footnotetext{
* Corresponding author: valkem2@mail.ru
} 
devaluation of the ruble, a substantial decrease in the incomes of the population, all that has led to the necessity to refuse from expensive imported products. Especially intensive are the processes of adaptation in regions with a poorly diversified economy and a predominance of the industrial sector, mining industries. A fundamental feature of the activation of owns production development is the need for sufficient financial investment in new agricultural production facilities and renovation of old ones.

This may lead to the emergence of issues related not only to financing, resources, investment, but also to the problem of maintaining the financial viability of the region as a subject of the Russian Federation. Nowadays, the deficit of regional budgets in most regions of Russia has become their constant characteristics. The study of the financial security of the region under conditions of import substitution in the agricultural sector presents a scientific task with practical access to the system of monitoring food security in connection with the financial aspects of security and creating a model for its management as well as determining the prospects for economic development [7, 8, 9]. The question about which level of security should be considered safe still remains open.

\section{Materials and Methods}

The research is based on a dialectical approach to the study of economic processes and phenomena. The object of the study is the industrial region, that is Kemerovo region very typical in terms of characteristics of the modern Russian economy in the crisis and postcrisis period. The subject of the research is financial security and food security as a sustainable feature of the region's economy.

The chronological depth of studying the problems associated with the actualization of the concepts of financial and food security is generally limited to the period 2013-2017. This period was chosen as the most vivid for intensification of security problems under the conditions of the world economic crisis. In our opinion this period allows us to identify the main characteristics of the phenomenon as a reflection of the cause-effect relationship. Therefore, in order to obtain reliable scientific knowledge the application of historical, evolutionary methods seems to be justified. The linkage of security research to the phases of the global economic crisis is due to economic and political tensions and attention to the security of the states and regions. The historical method is also based on the axiomatic acceptance of the evolutionary development of the economy. This is a characteristic of the dialectical approach which indisputably is the only scientific option for the research of economic phenomena in dynamics.

At the theoretical level the methods of abstraction, analysis and synthesis are used which help to view phenomena in interrelation with other elements and to identify the most significant features without reducing the overall accuracy of the study. The systemic principle in the study helps to move from food security assessments to assessing the financial security of the region based on the axiom that the problems of food security are in correlation with financial aspects.

The study of the interrelationships of food and financial security requires the use of statistical and econometric methods that allow the formalization of identified trends. Bringing them to a mathematically comparable basis, to a single system of coordinates allows comparing, generalizing and reaching a different level of cognition. The method of ascent from the abstract to the concrete reveals the content of higher-order phenomena, which is in our case the relationship of food security with other phenomena, indirectly or directly related to food security.

The financial security evaluation of the region is based on the methods of indicative analysis. Although, as experience shows, the conditions for which methods for assessing 
the level of financial (food, economic and other components) were developed differ from the current situation.

In particular, the methodological complexity may present an ambiguous definition of the material basis of financial security that is the financial system of the region, which consists of a number of elements such as banks, credit organizations, etc. The presence in the regions of elements functionally related to a larger scale of the country level, "dilutes" the integrity of the idea of the region financial system. Accordingly, financial flows also lose their regional localization. As a result, the concept of "food security" in the region correlated with the development of its own agricultural production, is largely based on financing from other regions sources which use of resources of a different level such as federal and others.

\section{Results and Discussion}

An active search for new business development opportunities continues even under the conditions of economic turbulence in the Russian banking sector. Special attention was paid to the work with the agro-industrial complex which confidently adapts to the new conditions of management and implementation of import substitution. Lending and loans to agriculture is extremely crucial factor in import substitution, which in the end should ensure the process of reduction of imported food and improve the country's food security. Import substitution as one of the ways to diversify the economy can be quite successful by combining the support for own production, export development and encouraging competition which will help to improve product quality and restrict prices.

The analysis of the results of import substitution in Kemerovo region, the region with industrial specialization, showed that the region has reached a stable growth path of increasing food and economic security. Kemerovo region is not included in the number of agricultural regions of Russia, but now fully provides itself with vegetables, poultry, meat, and eggs. The development of own agro-industrial production in the region is complicated by the problems inherent to other regions; they are significant depreciation of fixed assets, low investment activity and a lack of financially stable borrowers.

The conducted assessments of financial security allow to conclude that in the context of financial security the situation in the region can be characterized as a crisis. The indicators used do not disclose the whole range of problems and features of the financial and economic system. The threats exist and their impact is multifaceted. There is a need to classify threats and risks and assess their significance. In the zone of emergency crisis, the development of the system goes into the background; basically we have to solve the problems of survival. At the same time, the safety assessment parameters used are not sufficient. The present day situation necessitates the need for a change of the methodology for financial security assessing with taking into account new economic phenomena and factors. The main indicators of financial security are calculated in relation to the gross regional product. This makes sense and useful for revealing the situation and understanding how these or those trends affect the gross regional product being a key indicator of regional development.

The concept of the financial system of Russian region can not be limited to geographical and administrative borders, thus the influence of finance and banking on regional projects of import substitution is extremely diverse. If we talk about security assessments in the context of the financial system and the banking sector, the difficulty of creating an evidentiary basis is in the impossibility of a clear localization of the system. Each region depends on the federal center and there are complex inter-budgetary relations with the regions lacking their own banking system. The research also assessed the impact of individual factors related to food security and directly related to production and 
consumption data for gross regional product (GRP). The correlation between GRP and factors is considered in the following aspects. The balanced financial result of organizations, expenditures of the consolidated budget of the region, overdue total debt on liabilities, accounts payable of organizations, loans granted to individuals, external funds of legal entities and individuals, loans granted to organizations.

Empirically, the correlation analysis confirmed the stable and extensive relationship of GRP with the volume of loans granted to individuals and the accounts payable of organizations. The accounts payable of organizations testify to the need for deferred payment as a consequence of the uneasy financial condition of borrowers. The share of overdue loans in loans granted to organizations for the period from 2014 to 2016 increased significantly, negatively affecting the financial result of the banks themselves as well as the budgetary part. This situation influenced the level of financial security in the regions assessed as a crisis.

Under the conditions of a restricting access of Russian banks and industrial enterprises to long-term and inexpensive sources of credit abroad, the import substitution program requires serious credit investments. Compressing the banking system, reducing the number of banks impose restrictions on the credit component of the banking business. With liquidity surplus Russia's banking system is extremely cautious about borrowers whose solvency is falling.

As revealed by the conducted research, under the conditions of profitable items reduction the banking system aspires to expand segments of clients, to look for new ones paying attention to small and medium business. With the active support of agricultural lending from the state, this helps to develop home production and import substitution in this sector. Import substitution as a strategy has entered the stage of implementation brought the first results, but they are mostly of a breakthrough nature and are adherent to certain industries. The effect of import substitution has not yet been fully realized in 2015 with the growth of the agricultural sector of 3.1\% compared to 2014, and its share in GDP remains at $3.5 \%$, which is close to $3.2 \%$ in 2011 and 2014 accordingly.

The special problem of assessing food security becomes its evaluation in the scale of the region. The geographical scope of Russia initially formed the distribution of productive forces with this characteristic taken into account. A variety of factors of different nature such as labor resources, technological structure, distance from the center, financial resources, changes in the social and economic system, defense potential and other have given specificity to every region and agricultural production in many regions is not the dominant and leading industry.

Nowadays the specifics of the region are not taken into account in the monitoring system for food security and financial security. The methods are universal, but there can not be a single approach to all regions. The calculations are destined to be inaccurate since not all regions are able to become fully supplied with their food production. Thus the assessment of food and financial security of the regions are likely to be low. There arises a fundamental question as to whether it is reasonable as a goal to achieve the complete selfsufficiency of the region, which for historical reasons and natural factors has a powerful industrial potential and an orientation towards the export of energy resources. At the same time the reliability of such assessments will be reduced.

The increase in lending to agricultural enterprises will contribute to the development of the agricultural industrial complex and influence the gross regional product. On the one hand, this trend is positive as own agricultural production is developing and food security is enhancing. On the other hand, enterprises' accounts payable increase as well and taking into account the relatively low financial stability of agricultural enterprises, overdue accounts payable grow significantly. In its turn, this negatively affects the financial security of the region in general. 


\section{Conclusion}

The presented results are ambiguous as it is necessary to continue in-depth study of the relationship between GRP and loans, accounts payable in terms of subjects, terms, volumes, category of borrowers and industry. However, qualitative assessments make it possible to evaluate the objectivity of connections and to identify their most significant features. In this case, the assessments determine the need for an integrated approach to identifying the structure of GRP dependence on the parameters of the banking system in order to reveal the contribution of borrowers of the agricultural sector to the financial security of the region while increasing the region's food sovereignty. It is supposed that the link between the increased food security and the decrease of the regional financial security might be the result of the failure to localize the regional financial system and its immaturity. The further consideration includes the adaptation assessment of financial security of the region given the parameters characterizing the food security.

\section{References}

1. Sanctions: how and when the EU adopt restrictive measures (Euro Council, Brussel, 2018)

2. D. Gros, F. Mustilli, The effects of sanctions and counter-sanctions on EU - Russian trade flows (CEPS, Brussels, 2016)

3. B. Aris, Europ. Lead. Net. Pol. Brief., 6, 25 (2014)

4. S. Secrieru, Russia under sanctions: Assessing the damage, scrutinising adaptation and evasion (Polski Instytut Spraw Miedzynarodowych, Warszawa, 2015)

5. Z. Kutlina-Dimitrova, Chief Economist Note, 3, 45-51 (2015)

6. I. Fernald, G. John, I. Charles, Amer. Econ.Rev., 104:5, 44-49 (2014)

7. FAO, Russian's restrictions on imports of agricultural and food products: An initial assessment (Food and Agriculture Organization of the UN, Rome, 2014)

8. I. Bond, C. Odendahl, J. Rankin, Frozen: The politics and economics of sanctions against Russia (Center for Eurorean Reform, London, 2015)

9. M. Rodrigues, J. Monet. Econ., 57: 2, 175-188 (2010) 